\title{
Sensitive and Simple Determination of Diclofenac Sodium by Use of a Continuous Flow-Injection Procedure with Solid-Phase Spectroscopic Detection
}

\author{
P. Ortega-Barrales, A. Ruiz-Medina, M. L. Fernández-de Córdova and A. Molina-Diaz ${ }^{\dagger}$ \\ Department of Physical and Analytical Chemistry, Faculty of Experimental Sciences, University of Jaén, \\ 23071, Jaén, Spain
}

\begin{abstract}
A flow-through sensor for the determination of diclofenac sodium was developed, based on retention of the analyte on a Sephadex QAE A-25 anion-exchange resin packed in a flow-cell of $1 \mathrm{~mm}$ of optical path length, and monitoring of its intrinsic absorbance by UV-spectrophotometry at $281 \mathrm{~nm}$. Diclofenac could be determined in the concentration ranges $2.0-40.0,1.0-22.0$ and $0.5-14.0 \mu \mathrm{g} \mathrm{ml}^{-1}$ with RSD (\%) ranging from 1.05 to 1.53 for sample volumes of 300,600 and $1200 \mu$ l, respectively. The proposed sensor was satisfactorily applied to the rapid determination of diclofenac in commercial pharmaceutical preparations and in semi-synthetic pharmaceuticals containing diclofenac and paracetamol.
\end{abstract}

Keywords Diclofenac sodium, solid-phase spectrophotometry, FIA, flow-through sensor

Solid phase spectrometry (SPS) is a methodology based on the retention (preconcentration) of the analyte (or its chemical reaction product) on an active solid phase in combination with its direct measurement on that by the use of a non-destructive optical device, such as an UV-Vis spectrophotometric or spectrofluorometric detector. This is a relatively recent technique, which has demonstrated its applicability to a wide variety of inorganic and organic species in real samples. ${ }^{1,2}$ It shows interesting features, such as an improvement in selectivity and lower detection limits in addition to a significant increase in sensitivity as compared with the same procedure in homogeneous solution. However, SPS in the UV region has been scarcely exploited.

The integration of SPS with flow injection analysis (FIA) is also a new technique based on the retention and detection of the analyte on the active solid support placed in an appropriate flow cell into the optical detector. The retained species are eluted after reaching the detection zone and the analytical signal is developed, by the carrier itself or by another appropriate species, in order to keep the active support ready for the next sample. This integration combines the advantages of SPS (selectivity and sensitivity) and those inherent to a continuous-flow system: speed, automation, reduction of reagent and sample consumption, as well as a minor human participation. ${ }^{3-5}$

Diclofenac sodium (DS), a phenylacetic acid derivative, is a non-steroidal anti-inflammatory agent. This drug exhibits anti-inflammatory, analgesic and antipyretic activity. The exact mechanism has not been clearly established, but many of the actions appear to

† To whom correspondence should be addressed. be associated principally with the inhibition of prostaglandin synthesis.

It has been determined by a variety of analytical techniques, such as colorimetry ${ }^{6,7}$, ultraviolet ${ }^{8-11}$ and visible ${ }^{12-18}$ spectrophotometry, fluorometry ${ }^{19}$, gas $^{20-22}$ and liquid $^{23-25}$ chromatography, and flow injection analysis with spectrophotometric detection. ${ }^{26}$

Spectrophotometric methods provide practical and economical advantages over other ones. In most of them DS is determined indirectly by means of either the formation of colored species with reagents (such as Methylene Blue, Methylene Violet, copper(II) acetate, iodine, 2,3-dichloro-5,6-dicyanol, 2,4-dichloro-6-nitrophenol and ferric chloride/2,2-bipyridine) followed by extraction ${ }^{12-15,17,26}$ or via oxidation ${ }^{16,18}$ (with $\mathrm{KBrO}_{3}$, ceric ammonium sulfate or potassium ferricyanide). The sensitivity, precision and accuracy of these spectrophotometric methods are similar to those obtained by chromatographic methods. Nevertheless, they are time consuming and usually involve a solvent-extraction step.

In the present work, we propose a sensor for the determination of DS in pharmaceutical preparations combining solid phase UV-spectrophotometry with flow analysis (FIA). It is based on the retention of the analyte on a Sephadex QAE A-25 anion exchanger (used as solid support) in the flow cell and a direct measurement of its intrinsic absorbance on the UV region at $281 \mathrm{~nm}$. The sensitivity of the proposed sensor is comparable with that obtained by the most sensitive spectrophotometric methods found in the literature. A series of advantages with respect to the latter have been found, such as speed, high selectivity and a minor reagents consumption inherent to the use of flow injec- 


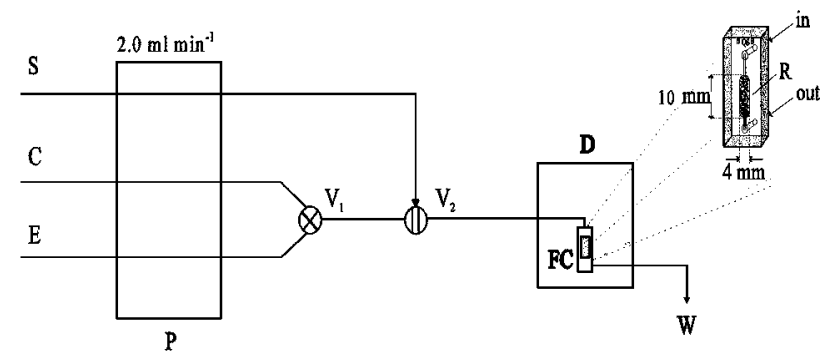

Fig. 1 Schematic diagram of the flow system: S, sample; C, carrier; E, eluent; $\mathrm{P}$, peristaltic pump; $\mathrm{V}_{1}$, selecting valve; $\mathrm{V}_{2}$, injection valve; D, spectrophotometric detector; FC, flowthrough cell; R, Sephadex QAE A-25; W, waste.

tion analysis (FIA), in addition to the possibility of applying it to the determination of DS in tablets also containing paracetamol.

\section{Experimental}

\section{Reagents and instrumentation}

All chemicals used were of analytical-reagent grade; doubly distilled water was used for the preparation of solutions and all dilutions.

A diclofenac stock solution (100 $\mathrm{mg} \mathrm{l}^{-1}$ as the sodium salt) was prepared from diclofenac sodium (Sigma). The solution was stored at $4^{\circ} \mathrm{C}$. Working standards were prepared daily from this solution, as required, by dilution with water.

Sodium acetate $(\mathrm{NaAc}) /$ acetic acid (HAc) buffers $(0.1$ and $0.4 \mathrm{M}, \mathrm{pH} 4.8$ ) were prepared from $\mathrm{NaAc}$ (Panreac) and HAc (Panreac) and used as a carrier and eluent solutions, respectively.

Sephadex QAE A-25 (40-120 $\mu \mathrm{m})$ anion-exchange resin (Aldrich) was used in the chloride form, without any preliminary treatment, as a solid support.

The instrumentation used included a four-channel Gilson Milnipuls-3 peristaltic pump with a rate selector, two Rheodyne Model 5041 injection and selection valves and a Unicam $8625 \mathrm{UV} / \mathrm{Vis}$ microprocessor controlled spectrophotometer. The latter was equipped with a Hellma 138-QS flow-cell $(1 \mathrm{~mm}$ light path and $50 \mu 1$ inner volume) and was connected to an IBM Personal System/2 Model 80286 computer running the 8625 Series Rate Software, and to an EPSON EPL5200 printer. Teflon tubing $(0.8 \mathrm{~mm}$ i.d) was also used.

\section{Procedure}

A flow diagram is shown schematically in Fig. 1. An aqueous solution containing DS was inserted into the carrier solution $(\mathrm{NaAc} / \mathrm{HAc}, \mathrm{pH} 4.8,0.1 \mathrm{M})$ and

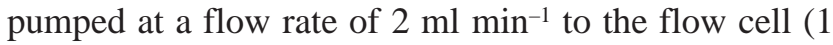
$\mathrm{mm}$ light path) where DS was retained on the support. The retention signal was monitored at $281 \mathrm{~nm}$; when it reached the maximum height, the concentrated analyte was eluted with an eluent solution (NaAc/HAc, $\mathrm{pH} 4.8$, $0.4 \mathrm{M}$ ), which was pumped to the cell by rotating the

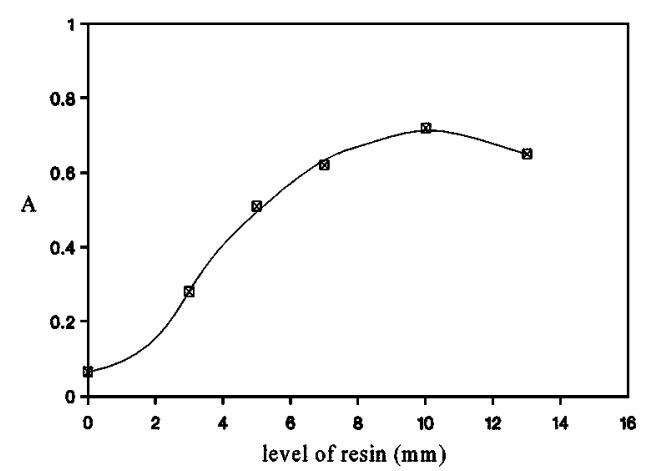

Fig. 2 Effect of the level of support in the flow cell. Diclofenac sodium $20 \mu \mathrm{g} \mathrm{ml}^{-1}$. Sample volume of $600 \mu \mathrm{l}$.

selecting valve, thus restoring the baseline.

\section{Sample preparation}

Tablets and capsules powder of DS were accurately weighed and dissolved in an appropriate amount of water using an ultrasonic bath for 3 min. Filtration through a $0.45 \mu \mathrm{m}$ membrane filter (Millipore) was performed to remove any remaining insoluble matter. The filtrate was transferred into a calibrated flask and then diluted to volume. Binary mixtures of DS and paracetamol were prepared by adding various amounts of one or another to the pharmaceuticals containing only paracetamol or DS, respectively, as active principle.

\section{Results and Discussion}

\section{Preliminary study}

The spectral features of the analyte in homogeneous solution and also that retained on a solid sorbent (Sephadex QAE A-25 anion-exchange) were previously established. The maximum absorption of DS sorbed on the solid support of the sensor appears at $281 \mathrm{~nm}$, thus showing a bathochromic shift of the maximum of the spectrum from solution $(276 \mathrm{~nm})$.

The signal is about 10-times higher than that obtained in solution, due to the preconcentration process of DS in the active sensing microzone into the flow cell of 1 mm optical path.

\section{Level of the packed flow cell}

The level of the resin in the flow cell was important. The optimum height of the packing level was $10 \mathrm{~mm}$ (Fig. 2). For this resin height, the whole light beam passed through the resin; with lower levels, the beam passed through the solution completely or partially and when the level was above the light beam, the area of analyte concentration fell outside the detection area.

Influence of $p H$, nature and concentration of carrier/eluent solutions

The influence of the nature of the carrier solution as 
Table 1 Analytical features of the method

\begin{tabular}{cccccc}
\hline Injected volume $/ \mu \mathrm{l}$ & Linear dynamic range $/ \mu \mathrm{g} \mathrm{ml}^{-1}$ & Equation $(r)$ & $\mathrm{RSD}, \%$ & ${\text { Detection limit } / \mu \mathrm{g} \mathrm{m} \mathrm{l}^{-1}}^{\text {Sampling frequency } / \mathrm{h}^{-1}}$ \\
\hline 300 & $2.0-40.0$ & $\begin{array}{c}A=0.018+0.0208 c \\
(r=0.9991)\end{array}$ & 1.05 & 0.44 & 12 \\
600 & $1.0-22.0$ & $\begin{array}{c}A=0.015+0.0382 c \\
(r=0.9991)\end{array}$ & 1.16 & 0.24 & 11 \\
1200 & $0.5-14.0$ & $\begin{array}{c}A=0.026+0.0612 c \\
(r=0.9992)\end{array}$ & 1.53 & 0.13 & 9 \\
& & & \\
\hline
\end{tabular}

$A=$ absorbance; $c=$ concentration of DS; $r=$ regression coefficient.

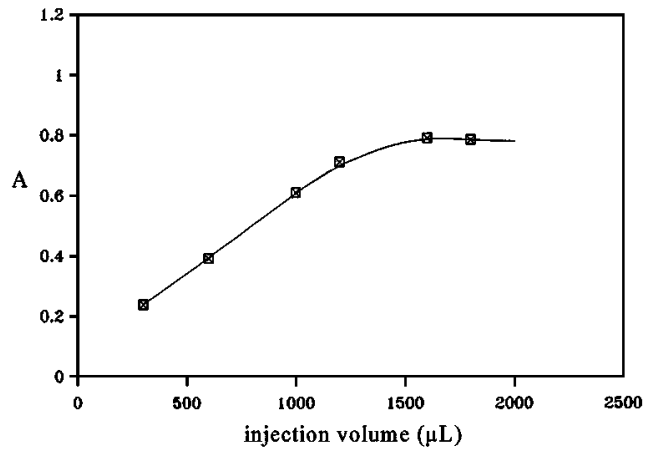

Fig. 3 Effect of the sample volume for $10 \mu \mathrm{g} \mathrm{ml}^{-1}$ of diclofenac sodium.

well as its $\mathrm{pH}$ value were studied by using various buffer solutions: formic acid/formate $(\mathrm{pH} 3)$, citric acid/citrate $(\mathrm{pH} 4), \mathrm{HAc} / \mathrm{NaAc}(\mathrm{pH} \mathrm{3.8,} 4.8$ and 5.5) and $\mathrm{KH}_{2} \mathrm{PO}_{4} / \mathrm{K}_{2} \mathrm{HPO}_{4}(\mathrm{pH} 6$ and 7). The results showed that the HAc/NaAc ( $\mathrm{pH}$ 4.8) buffer solution provided higher sensitivity. The influence of the concentration of the carrier solution chosen was studied in the 0.025 to $0.1 \mathrm{M}$ range, this latter concentration providing the highest analytical signal. It could be checked that the $\mathrm{HAc} / \mathrm{NaAc}(\mathrm{pH} 4.8$ ) carrier solution, itself, eluted the analyte from the resin when its concentration was sufficiently high. Therefore, various $\mathrm{HAc} / \mathrm{NaAc}$ solutions with concentrations ranging from 0.1 to $0.5 \mathrm{M}$ were tested as eluent solutions and a $0.4 \mathrm{M}$ concentration was chosen, because it provided the highest sampling rate and a complete achievement of the baseline.

\section{Effect of sample volume on sensitivity}

One of the main advantages of the sensor is a potential increase in the sensitivity along with an increase in the sample volume taken for analysis. The effect of this variable on the analytical signal could be assessed by passing through the flow cell different volumes of solution with the same concentration of analyte.

In Fig. 3, the variation of sensitivity with increasing sample volume injected (from 300 to $1800 \mu \mathrm{l}$ ) is shown. It can be seen that the absorbance increased linearly up to $1200 \mu \mathrm{l}\left(A=0.070+5.36 \times 10^{-4} v, r=0.9999\right)$ with increasing injection volume $(v, \mu \mathrm{l})$. Higher volumes did not increase the signal.

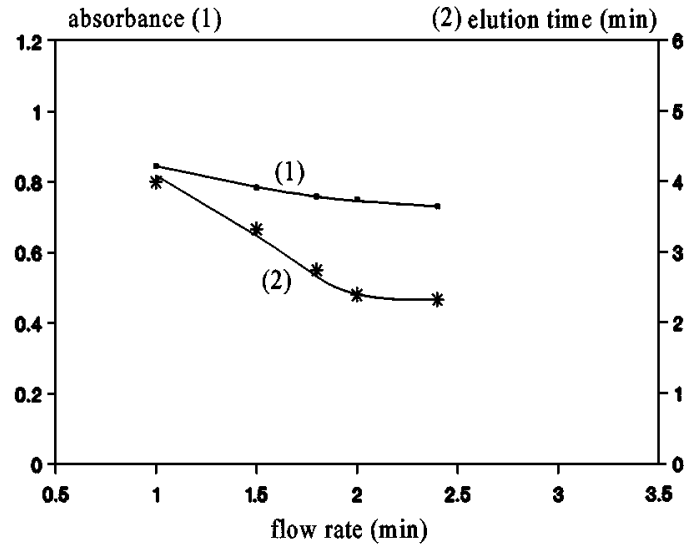

Fig. 4 Effect of the flow-rate in the absorbance and elution time: diclofenac sodium, $20 \mu \mathrm{g} \mathrm{ml}^{-1}$; sample volume, $600 \mu \mathrm{l}$.

\section{Effect of flow-rate}

Figure 4 shows the influence of the flow-rate on the measurement of $20 \mu \mathrm{g} \mathrm{ml}^{-1}$ DS solution using a $600 \mu \mathrm{l}$ injection volume. As can be seen, a change in the flow-rate from $1-2.4 \mathrm{ml} \mathrm{min}^{-1}$ decreased the analytical signal and the elution time and, consequently, allowed a higher sampling frequency. A flow-rate of $2 \mathrm{ml} \mathrm{min}^{-1}$ was adopted as a compromise (the signal decreases $11 \%$ against $40 \%$ in the elution time, in comparison with those for $1 \mathrm{ml} \mathrm{min}-1)$.

\section{Features of the proposed method}

The analytical figures of advantage of the proposed sensor for three different sample volumes $(300,600$ and $1200 \mu \mathrm{l})$ are given in Table 1 . The sensitivity of the proposed method (FIA ion-exchange resin phase absorptiometry) has been compared with that of FIA solution phase absorptiometry under the same conditions, but without using a solid support. The SPS-FIA method's sensitivity is more than 10-times higher than that of the corresponding solution method for a $600 \mu \mathrm{l}$ injection volume. The sensitivity is, moreover, comparable to that from the most sensitive spectrophotometric methods described in bibliography $y^{7,10,12}$ (all of them based in a derivative reaction usually followed by solvent extraction). In addition, the proposed method is speeder and cheaper because there is no need of both a derivative reaction and a solvent extraction. The precision of the method, expressed as RSD, was studied for 
Table 2 Effect of foreign species on the determination of 20 $\mu \mathrm{g} \mathrm{m} \mathrm{l}^{-1}$ of diclofenac

\begin{tabular}{lc}
\hline Foreign species & $\begin{array}{c}\text { Tolerance } \\
\left(\mu \mathrm{g} \mathrm{ml}^{-1} \text { interferent } / \mu \mathrm{g} \mathrm{ml} \mathrm{m}^{-1} \text { diclofenac }\right)\end{array}$ \\
\hline Lactose & 250 \\
Saccharose & 50 \\
Paracetamol (acetaminophen $)$ & 25 \\
Bencylic alcohol & 5 \\
Saccharine & 1.25 \\
Vitamin $\mathrm{B}_{1}$ & 0.25 \\
Vitamin $\mathrm{B}_{6}$ & 2 \\
Vitamin $\mathrm{B}_{12}$ & 1 \\
\hline
\end{tabular}

each sample volume injected using ten replicated injections of solutions containing 40, 20 and $15 \mu \mathrm{g} \mathrm{ml}^{-1}$ of DS for 300, 600 and $1200 \mathrm{ml}$ of sample volume, respectively. The detection limit was calculated by using the $3 \sigma$ recommendation. The sampling throughput decreased lightly as the injection volume increased.

\section{Effect of foreign species}

The interference of those species commonly accompanying DS in pharmaceuticals was studied. Table 2 gives the tolerance limits (expressed as w/w ratio), for the species studied on the determination of $20 \mu \mathrm{g} \mathrm{ml}^{-1}$ of DS for an injection volume of $600 \mu \mathrm{l}$. The maximum level tolerated was taken as that causing a difference in the signal not larger than $5 \%$. As can be seen, the common excipients and other species found in the preparations will not interfere with the method, because the amounts tolerated are much higher than those usually present in pharmaceuticals.

Diclofenac is usually supplied alone as active principle or, at the most, associated with paracetamol, being this latter a serious interferent in its spectrophotometric determination..$^{9,21}$ It should be emphasized that there is a high tolerance level of the method to the presence of paracetamol: the same FIA UV spectrophotometric procedure in a homogeneous solution tolerates only a 0.67 $(\mathrm{w} / \mathrm{w})$ ratio paracetamol/DS against a $25(\mathrm{w} / \mathrm{w})$ ratio in the proposed method, that is, about 40-times higher. This fact allows the determination of DS in pharmaceuticals also containing paracetamol.

It should also be noted that a higher tolerance level exists to the presence of vitamins $\mathrm{B}_{1}, \mathrm{~B}_{6}$ and $\mathrm{B}_{12}$, as compared with the same FIA UV spectrophotometric procedure in a homogeneous solution without using a solid support in the flow cell. In the latter, the tolerance limits (w/w) to these vitamins were $0.07,0.07$ and 0.3 , respectively. Therefore, the tolerance level to these vitamins in the SPS-FIA method here developed is respectively about 4,30 and 4 times higher than that in the solution method.

\section{Application of the method}

The proposed sensor was applied to the determination
Table 3 Determination of diclofenac in pharmaceutical preparations

\begin{tabular}{lccc}
\hline $\begin{array}{c}\text { Pharmaceutical } \\
\text { preparation }\end{array}$ & $\begin{array}{c}\text { Diclofenac } \\
\text { content/mg }\end{array}$ & $\begin{array}{c}\text { Diclofenac found } \\
\text { by the proposed } \\
\text { method }^{\mathrm{a}}(\mathrm{mg} \pm \text { SD) }\end{array}$ & $\begin{array}{c}\text { Recovery } \\
\%\end{array}$ \\
\hline $\begin{array}{c}\text { DiclofenacoDi- } \\
\text { Retard }\end{array}$ & 100 & $97( \pm 2)$ & 97.4 \\
$\begin{array}{c}\text { Diclofenaco } \\
\text { Llorens }^{\mathrm{c}}\end{array}$ & 75 & $75.2( \pm 0.8)$ & 100.3 \\
Voltaren $^{\mathrm{d}}$ & 50 & $49( \pm 1)$ & 98 \\
$\begin{array}{c}\text { Diclofenaco- } \\
\text { Lepori }^{\mathrm{e}}\end{array}$ & 50 & $48.5( \pm 0.2)$ & 97 \\
\hline
\end{tabular}

a. Data are based on the average obtained from three determinations.

b. Tablets (from Llorens, Ltd., Barcelona, Spain) containing diclofenac sodium $100 \mathrm{mg}$ and excip. q.s.

c. Ampoules (from Llorens, Ltd., Barcelona, Spain) containing diclofenac sodium $75 \mathrm{mg}$ and bencylic alcohol $120 \mathrm{mg}$.

d. Tablets (from CIBA-GEIGY, Ltd., Barcelona, Spain) containing diclofenac sodium $50 \mathrm{mg}$, lactose and excip. q.s.

e. Capsules (from Farma-Lepori, Ltd., Barcelona, Spain) containing diclofenac sodium $50 \mathrm{mg}$ and excip. q.s.

of DS in pharmaceuticals using the direct calibration method proposed for an injection volume of $600 \mu \mathrm{l}$. As can be seen in Table 3, the results found for this method are in accordance with the theoretical content of DS given by the manufacturers, thus confirming the validity of the sensor proposed in this paper. In some pharmaceuticals, DS is accompanied by paracetamol, but they are not available in Spanish Pharmacopoeia. Thus, semi-synthetic pharmaceuticals were prepared by adding known amounts of either paracetamol or DS to commercial preparations containing respectively, the other active principle. Results, shown in Table 4, indicate that it is possible to determine satisfactorily DS in pharmaceuticals in the presence of paracetamol by using the UV spectrophotometric sensor. This is due to the selective retention and concentration of DS in the active solid phase. Paracetamol does not originate any analytical signal, because at the working $\mathrm{pH}$ its phenol group is not dissociated, and therefore the anion exchanger cannot retain it.

The UV spectrophotometric flow-through sensor for DS developed in this paper by means of a SPS-FIA integration brings together the advantages of both methodologies: selectivity and sensitivity (from SPS) and speed, reduction of sample consumption and minor human participation (from FIA). The use of the solid phase in the unsegmented continuous-flow system provides a very important increase in selectivity (in addition to that of sensitivity). This allows the determination of DS in the presence of serious interferents (species such as paracetamol) in conventional spectrophotometric procedures (either in batch or in automatic modes) in spite of the UV spectrophotometric nature of the method. In addition, the absence of any derivative reaction makes the method very simple and 
Table 4 Determination of diclofenac in semi-synthetic pharmaceutical preparations

\begin{tabular}{cccc}
\hline $\begin{array}{c}\text { Pharmaceutical } \\
\text { preparation }\end{array}$ & $\begin{array}{c}\text { Diclofenac: } \\
\text { Paracetamol }\end{array}$ & $\begin{array}{c}\text { Diclofenac found } \\
\text { by the proposed } \\
\text { method }^{\mathrm{a}}(\mathrm{mg} \pm \mathrm{SD})\end{array}$ & $\begin{array}{c}\text { Recovery } \\
\%\end{array}$ \\
\hline Voltaren $^{\mathrm{b}}$ & $50: 50$ & $48.7( \pm 0.2)$ & 97.4 \\
Diclofenaco $^{\mathrm{a}}$ & $50: 500$ & $49.4( \pm 0.8)$ & 98.8 \\
Llorens $^{\mathrm{c}}$ & $75: 75$ & $73( \pm 1)$ & 97.3 \\
Duorol $^{\mathrm{d}}$ & $100: 500$ & $75.8( \pm 0.5)$ & 101 \\
Termalgin $^{\mathrm{e}}$ & $50: 500$ & $49.5( \pm 0.2)$ & 100.3 \\
\end{tabular}

a. Data are based on the average obtained from three determinations.

b. Tablets (from CIBA-GEIGY, Ltd., Barcelona, Spain) containing diclofenac sodium $50 \mathrm{mg}$, lactose and excip. q.s.

c. Ampoules (from Llorens, Ltd., Barcelona, Spain) containing diclofenac sodium $75 \mathrm{mg}$ and bencylic alcohol $120 \mathrm{mg}$.

d. Tablets (from Antibioticos Farma, Ltd., Madrid, Spain) containing paracetamol $500 \mathrm{mg}$ and excip. q.s.

e. Tablets (from Sandoz-Pharma, Ltd., Barcelona, Spain) containing paracetamol $500 \mathrm{mg}$ and excip. q.s.

inexpensive, thus being very appropriate for routine analytical control of pharmaceuticals.

The authors are grateful to the Dirección General de Enseñanza Superior (DGES) of the Ministerio de Educación y Cultura (Project No. PB97-0849), for financial support.

\section{References}

1. P. Ortega Barrales, M. L. Fernández de Córdova and A. Molina Díaz, Anal. Chem., 70, 271 (1998).

2. M. L. Fernández de Córdova, A. Ruiz Medina and A. Molina Díaz, Fresenius' J. Anal. Chem., 44, 357 (1997).

3. U. Hase and K. Yoshimura, Analyst[London], 117, 1501 (1992).

4. Z. Gong and Z. Zhang, Anal. Chim. Acta, 339, 161 (1997).

5. P. Ortega-Barrales, M. J. Ayora-Cañada, A. Molina-Díaz, S. Garrigues and M. De la Guardia, Analyst[London], 124,
579 (1999).

6. C. S. Sastry, A. R. M. Rao and T. N. V. Prasad, Anal. Lett., 20, 349 (1987).

7. S. C. Mathur, Y. Kumar, P. B. N. Prasad, A. C. S. Rao, Y K. S. Rathore and S. C. Gupta, Indian Drugs, 31, 447 (1994).

8. Y. K. Arrawal, V. P. Udapyay and S. K. Menon, Indian J. Pharm. Sci., 50, 58 (1988).

9. H. Fabre, S. W. Sun, B. Mandrou and H. Maillols, Analyst[London], 118, 1061 (1993).

10. M. S. Bhatia and S. R. Dhaneshwar, Indian Drugs, 32, 446 (1995).

11. M. S. Bhatia, S. G. Kashedikar and S. C. Chaturvedi, Indian Drugs, 33, 213 (1996).

12. S. P. Sastry, A. S. R. Prasad Tirpeneni and A Suryanarayama, Analyst[London], 114, 513 (1989).

13. S. Agatanovic'-Kustrin, L. Zivanovic, D. Radulovic and M. Vasiljeciv, Analyst[London], 116, 753 (1991).

14. Y. K. Agrawal and K. Shivramchaudra, J. Pharm. Biomed. Anal., 9, 97 (1991).

15. B. V. Kamath, K. Shivram, G. P. Oza and S. Vangani, Anal. Lett., 26, 665 (1993).

16. B. V. Kamath and K. Shivram, Anal. Lett., 26, 903 (1993).

17. J. C. Botello and G. Pérez-Caballero, Talanta, 42, 105 (1995).

18. R. Vaidya and R. S. Parab, Indian Drugs, 32, 194 (1995).

19. L. A. Carrera, M. Rizk, Y. El-Shabrawy, N. A. Zakhari and S. S. Toubar, J. Pharm. Biomed. Anal., 13, 1331 (1995).

20. J. V. A. Schweizer, D. B. Willis, J. Kendall and M. J. Kendall, J. Chromatogr., 195, 421 (1980).

21. W. Schneider and P. H. Degen, J. Chromatogr., 217, 263 (1981).

22. B. Henning, A. Steup and R. Benecke, Pharmazie, 13, 1307 (1987).

23. D. Grangjean, J. C. Beolor, M. T. Quincon and E. Savel, J. Pharm. Sci., 78, 247 (1989).

24. H. Chan, K. H. Vyas and K. Wnuck, Anal. Lett., 15, 1649 (1982).

25. A. N. Other, S. Godbilon, G. Gauron and J. P. Metayer, $J$ Chromatogr., 338, 151 (1985).

26. B. V. Kamath, K. Shivram and A. C. Shah, J. Pharm. Biomed. Anal., 12, 343 (1994).

(Received April 5, 1999)

(Accepted July 1, 1999) 